\title{
New application of purse string suture in skin cancer surgery
}

\author{
Paolo Fioramonti | Valentina Sorvillo | Michele Maruccia | Federico Lo Torto I Marco Marcasciano | \\ Diego Ribuffo I Emanuele Cigna
}

Department of Surgery, Unit of Plastic,

Reconstructive and Aesthetic Surgery, Policlinico

Umberto I Hospital, Sapienza University of Rome,

Rome, Italy

Correspondence

F Lo Torto, MD, Via Ettore Fieramosca

200, Rome 00159, Italy.

Email: federicolotorto@gmail.com
Closure of large wounds may require full-thickness skin grafts, but their use is burdened by donor tissue availability and morbidity; the use of the purse string technique is an elegant way to overcome this problem. The study highlights the gain in terms of graft donor site morbidity and oncological radicality. The study included a group of 47 patients who underwent surgical excision for skin cancer and whose wounds were covered using a purse string suture and a skin graft. Radius of the defect left was measured after the lesion's excision and after the purse string suture. Thereafter, the difference between the initial defect area and the area after purse string suture was calculated. Initial defects ranged from 3.85 to $61.5 \mathrm{~cm}^{2}$. After skin graft, the purse string suture ranged between 2.2 and $40 \mathrm{~cm}^{2}$ (mean area $=14$ $\mathrm{cm}^{2}$ ). Gained area before the graft measured from 1.3 to $21.5 \mathrm{~cm}^{2}$ (mean gained area $=7.1 \mathrm{~cm}^{2}$ ). Average reduction was $33 \%$. The technique allows a reduction of the size of the area to be grafted and the skin graft donor area, thus increasing the possibility of the feasibility of full-thickness grafts. In addition, it allows an optimal observation both of the area of tumour excision and margins during follow-up controls.

\section{KE YW ORDS}

purse string suture, round block, wound closure

\section{1 | INTRODUCTION}

Closure of large wounds is often challenging, and results are not always what are expected. This is especially true for defects of the facial area, where aesthetics are relevant, and for the scalp, where skin elasticity is poor, and only small skin advancement can be performed.

Placement of a flap is the most used and elegant technique to allow closure of a great number of defects. ${ }^{1}$ Advancement, rotation, transposition, or perforator flaps are only some of the possibilities that plastic surgeons have in their armamentarium. These techniques are only practicable for small lesions and when perilesional skin has enough elasticity. ${ }^{2}$

A different reconstruction possibility is to place a full- or split-thickness skin graft; this surgical approach may require an extensive donor area and its related postoperative treatment. Furthermore, skin graft surgery is often characterised by non-optimal cosmetic outcomes, with a sharp colour contrast between grafted and surrounding skin and contour irregularities. ${ }^{3}$ This is particularly true if split-thickness skin grafts are applied and in particular areas such as the scalp where skin graft results in alopecia.

Improved suture techniques may allow primary closure or facilitate the subsequent development of smaller grafts. Thanks to this artifice, defects that could not be completely closed by primary intention could be entirely closed through a smaller skin graft. ${ }^{4}$

This study describes a clinical application of the purse string suture that releases tension at $360^{\circ}$ and allows the placement of a graft smaller than the expected one (Figures 1 and 2). It is a rapid and simple procedure to perform: tension placed on the suture uniformly advances the skin from the entire periphery of the wound, resulting in a significant reduction of the defect size and enhancement of haemostasis at the wound edge., 


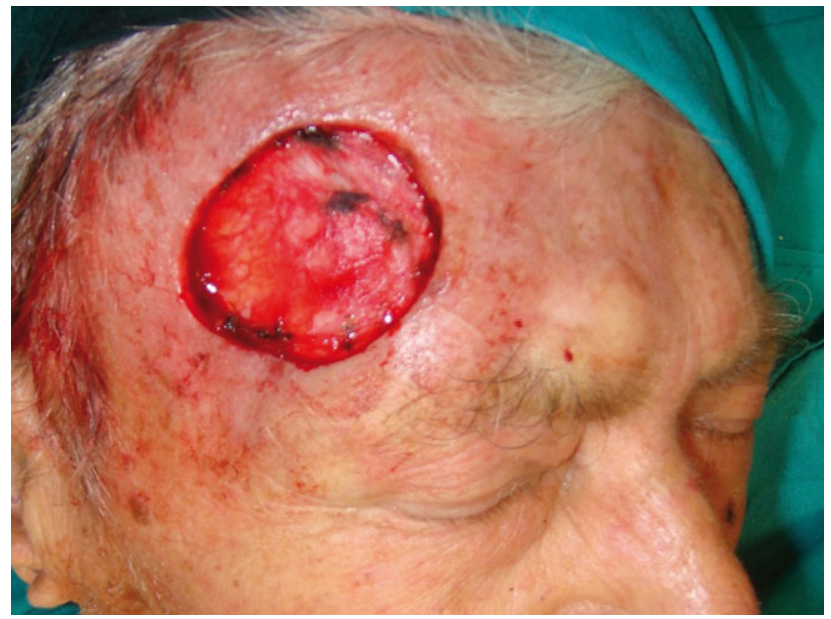

FIGURE 1 Patient 1: A 79-year-old woman who underwent excision of a skin tumour of the forehead

\section{2 | MATERIALS AND METHODS}

The study included a group of 47 patients who underwent surgical excision for a skin cancer, previously diagnosed by biopsy, between January 2012 and July 2016. All excisions that left a round defect were sutured using a purse string "round block" technique with the addition of a skin graft in the remaining central area (Figures 3-5).

Epidemiological analysis showed an average age of 69,5 years in patients (31-84). No relevant difference was demonstrated between 2 genders ( 23 females, 24 males).

All lesions were localised on the scalp.

All cases were selected because it was not possible to use flaps. In fact, in 10 patients, losses of substance were too large to appeal for the use of a local flap. In 30 patients, the perilesional skin presented preneoplastic lesions (ie, Keratoses, Bowen's disease, etc.). In 7 patients, the general conditions were so poor or anticoagulants were used that a short surgical time was recommended.

Generally, no undermining of the wound margins was performed, as suggested by Hirshowitz and Lindenbaum, ${ }^{7}$ to

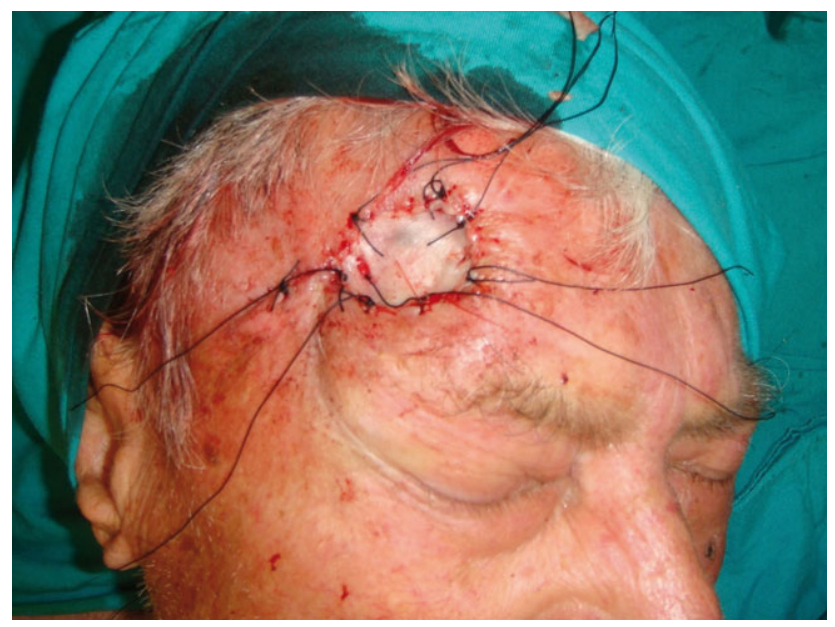

FIGURE 2 Patient 1: The resulting skin defect was closed using a purse string suture and a skin graft

\section{Key Messages}

- Closure of large wounds is often challenging and results are not always what expected

- the purse string suture is a round block suture

- the purse string suture was applied to reduce the defect after skin cancer excision

- the mean gained area was of $33 \%$

- the proposed technique allows limiting the skin graft donor site area

maintain maximum vascularity. A $2 / 0,3 / 0$, or $4 / 0$, a polydioxanone suture was used on the deep dermal layer, and the wound margins were progressively approximated as much as possible. After this first step, the remaining defect was covered by a graft. In all cases, it was possible to use a fullthickness skin graft as a result of the substantial area reduction, so the final aesthetic result was markedly better than using a partial thickness skin graft (Figures 6-13).

All lesions were sent for histological analysis.

All patients were first dressed 5 days after surgery and then every 3 days until external stitches have been removed. Complications were reported.

During surgery, the radius of the defect left after the lesion's excision was measured, and then, it was measured again after the purse string suture had been performed. During data processing, the area of the defect was calculated before and after purse string suture, likening it to that of a circle $\left(r^{2} \pi\right)$. Thereafter, the difference between the initial defect area (IDA) and the area after purse string suture (APSA) was calculated. The area calculated in this way corresponded to the skin area gained before graft (GA).

$$
\mathrm{IDA}-\mathrm{APSA}=\mathrm{GA}
$$

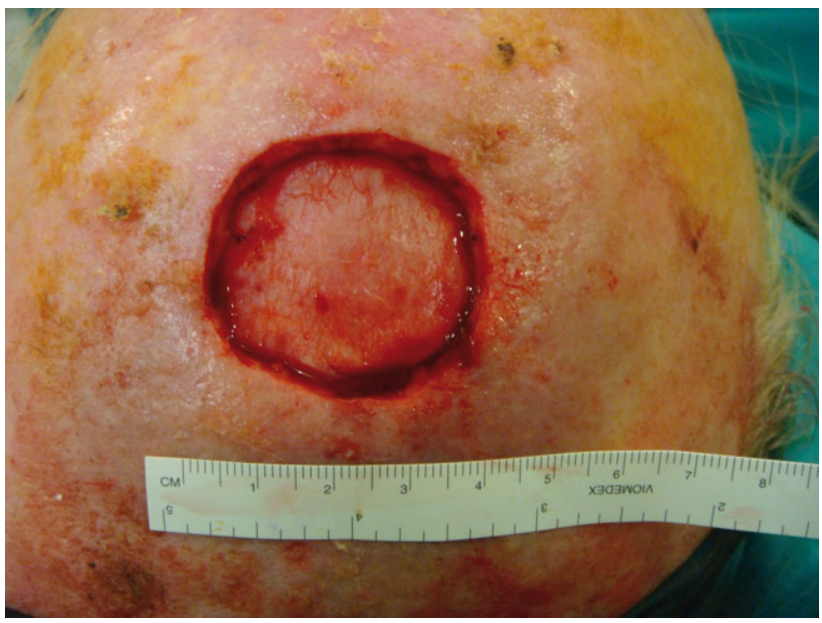

FIGURE 3 Patient 2: An 81-year-old woman who underwent excision of a squamous cell carcinoma of the scalp 


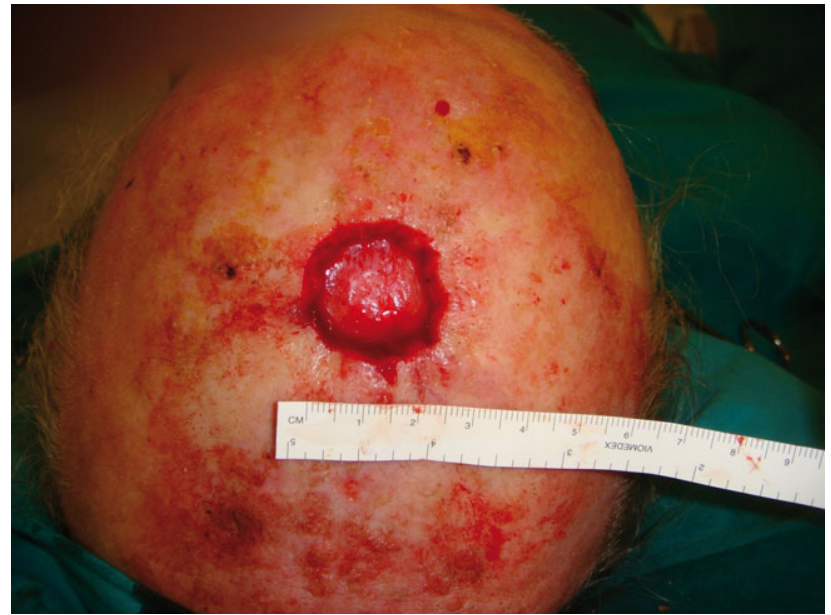

FIGURE 4 Patient 2: The resulting skin defect was closed using a purse string suture. The larger diameter was $4 \mathrm{~cm}$, which decreased to $2.2 \mathrm{~cm}$ after the suture

Finally, thanks to the data collected, the percentage of area gained was calculated. In addition, epidemiological analysis was conducted to determine the most frequent histological type of lesions, the average age of patients, and the most common localisation.

\section{3 | RESULTS}

Histological results included 3 melanomas (6\%), 6 squamous cell carcinomas (12\%), 36 basal cell carcinomas (78\%), and 2 keratoacanthoma (4\%) (Table 1).

After removal of the skin lesion with an adequate margin, a round or ovoid defect varying in size from 3.85 to $61.5 \mathrm{~cm}^{2}$ remained (mean area $=21.1 \mathrm{~cm}^{2}$ ). After the purse string suture was performed, the remaining defects ranged between 2.2 and $40 \mathrm{~cm}^{2}$ (mean area $=14 \mathrm{~cm}^{2}$ ). Therefore, the gained area before the graft measured 1.3 to $21.5 \mathrm{~cm}^{2}$ (mean gained area $=7.1 \mathrm{~cm}^{2}$ ). The mean gained area was $33 \%$, from a minimum of $21 \%$ to a maximum of $43 \%$, still in

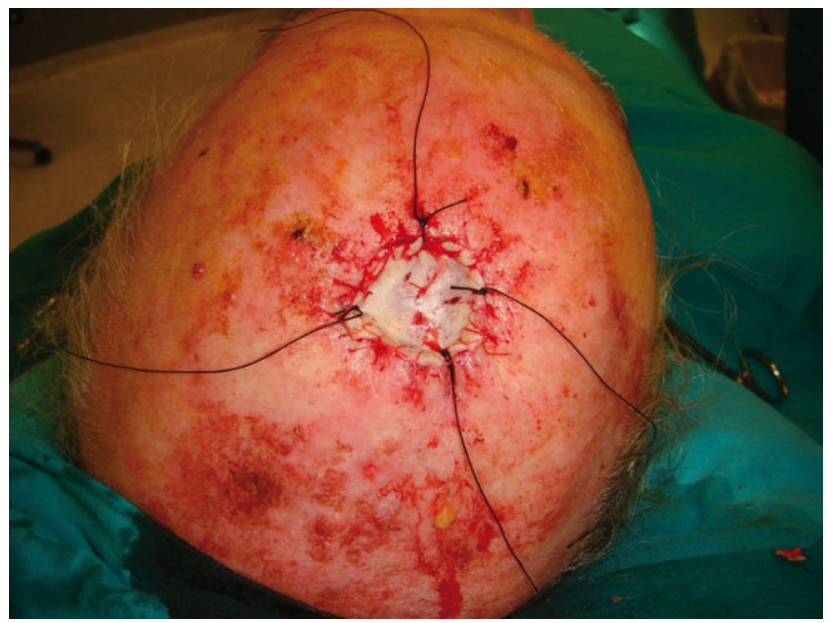

FIGURE 5 Patient 2: Full-thickness skin graft

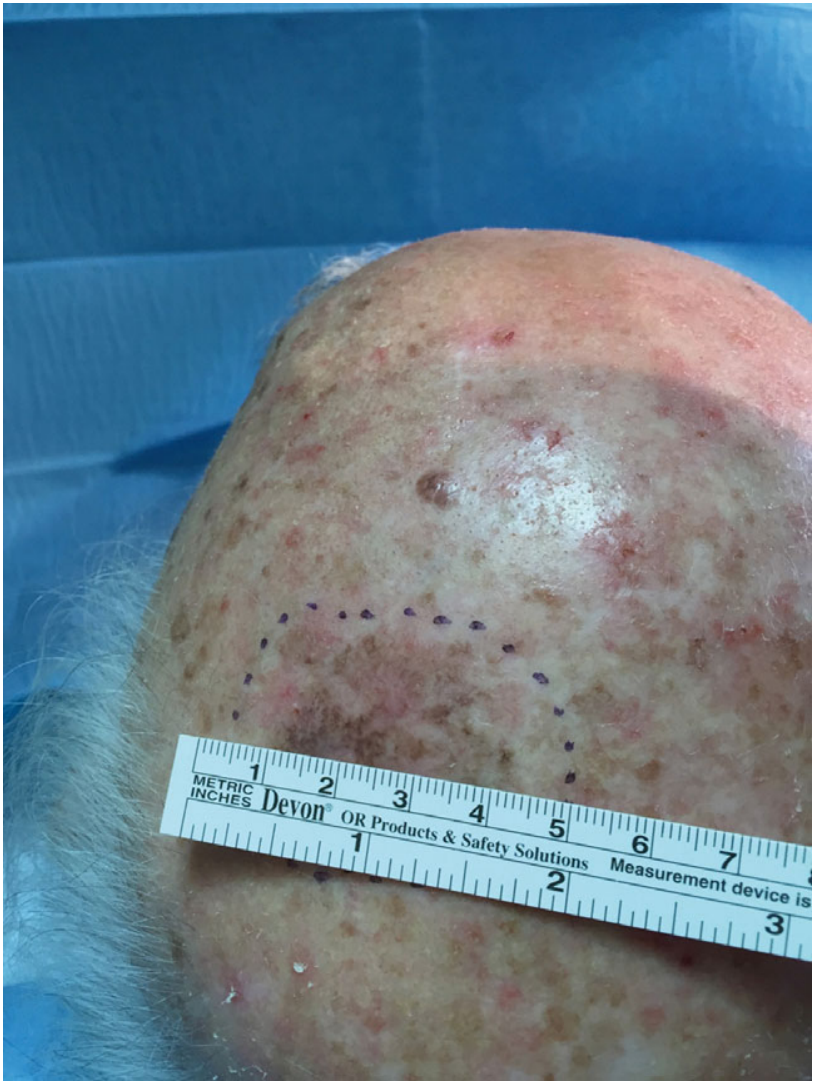

FIGURE 6 Patient 3: A 78-year-old man before excision of a skin tumour in the left parietal region. The larger diameter was $5 \mathrm{~cm}$

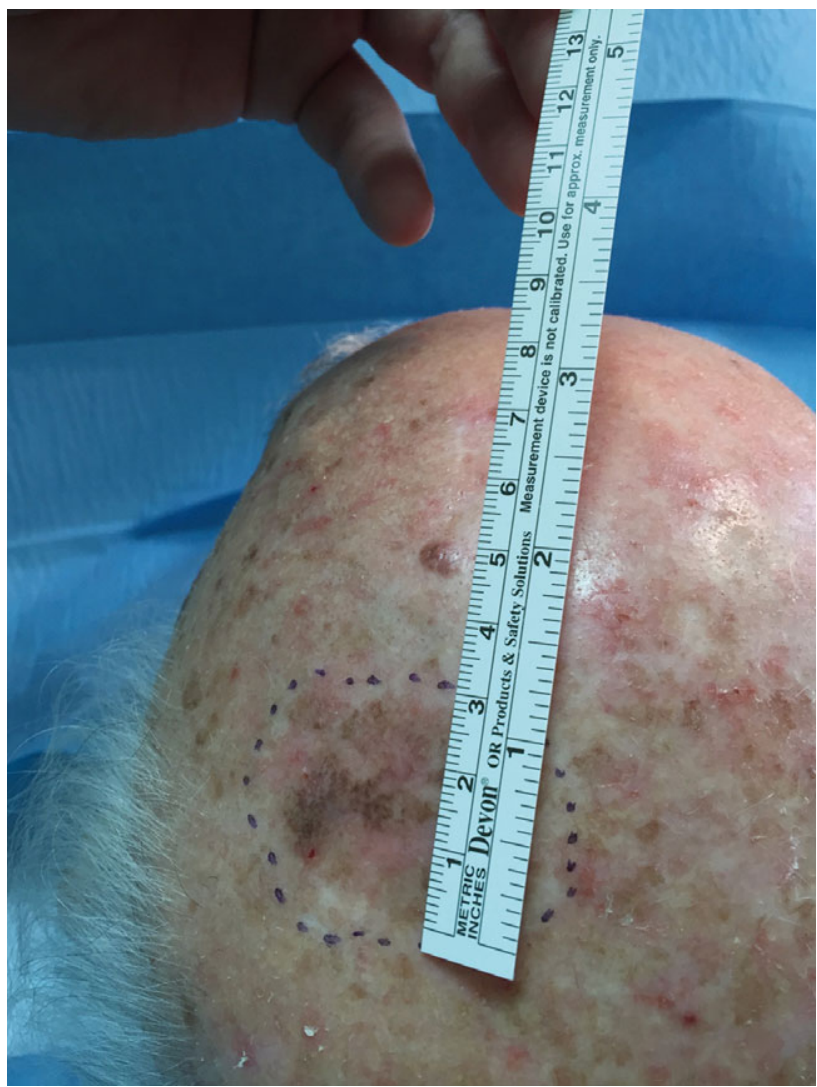

FIGURE 7 Patient 3: The smaller diameter was $3 \mathrm{~cm}$ 


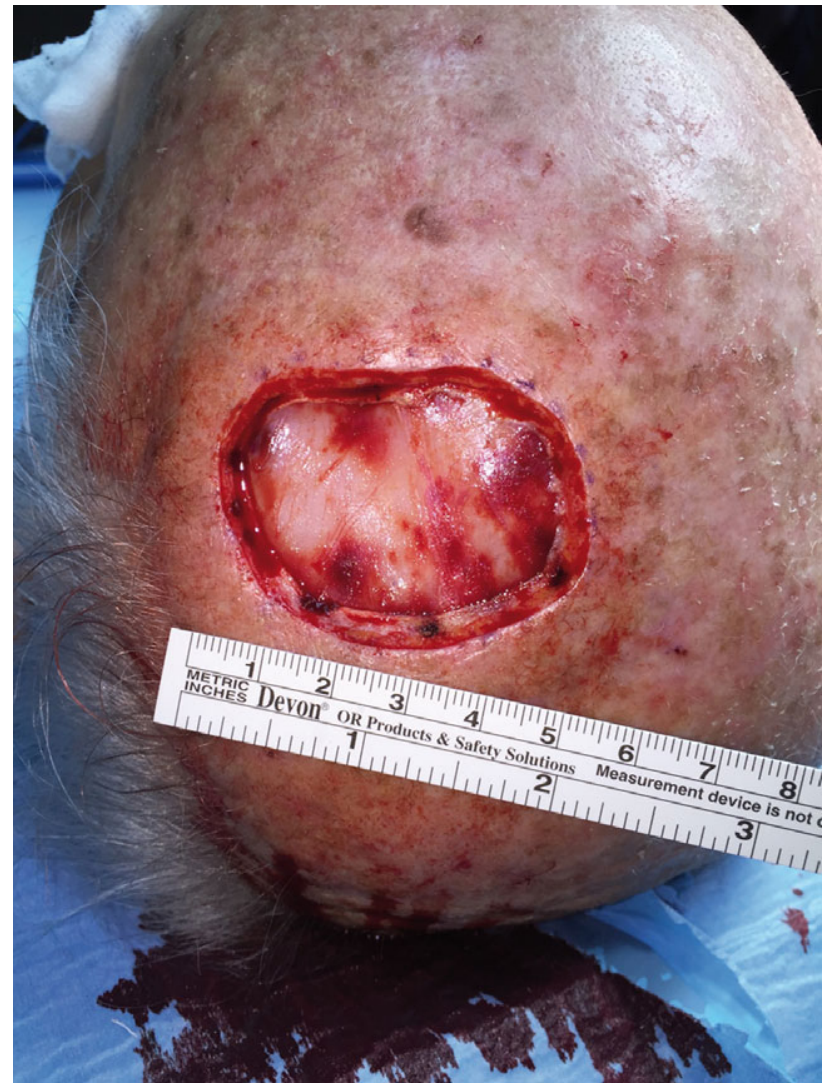

FIGURE 8 Patient 3: The resulting skin defect (larger diameter)

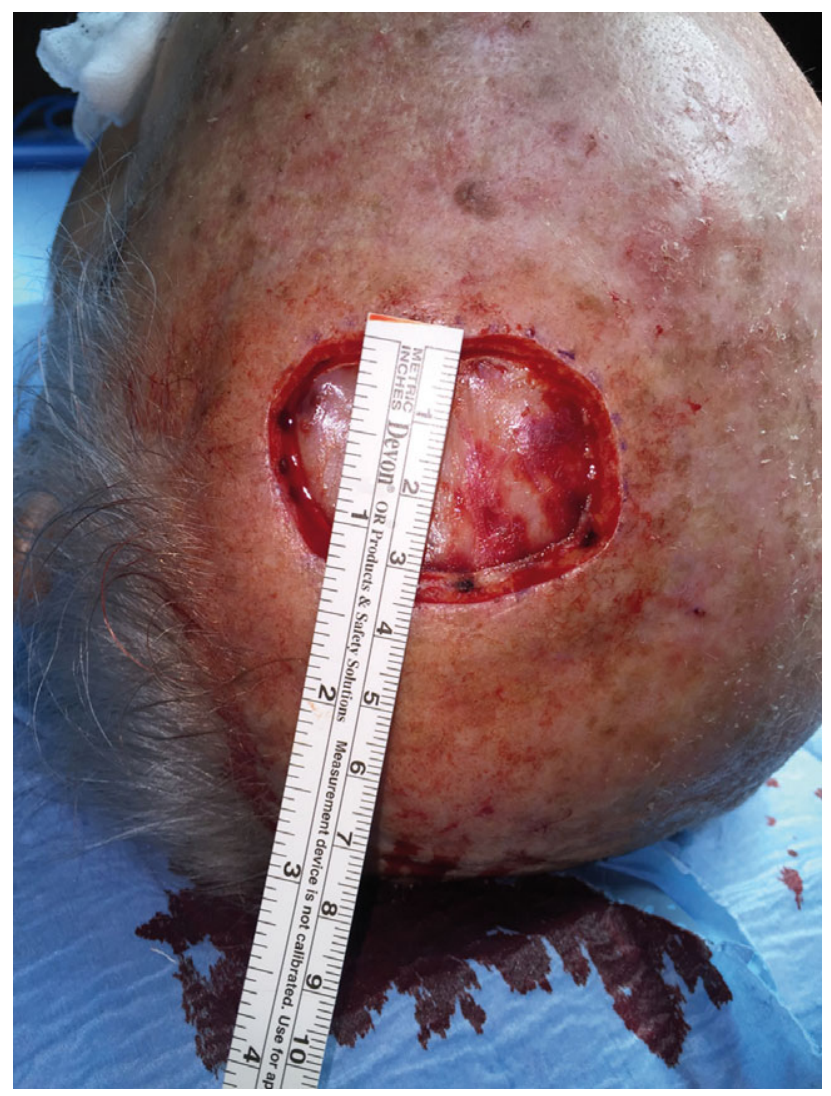

FIGURE 9 Patient 3: The resulting skin defect (smaller diameter)

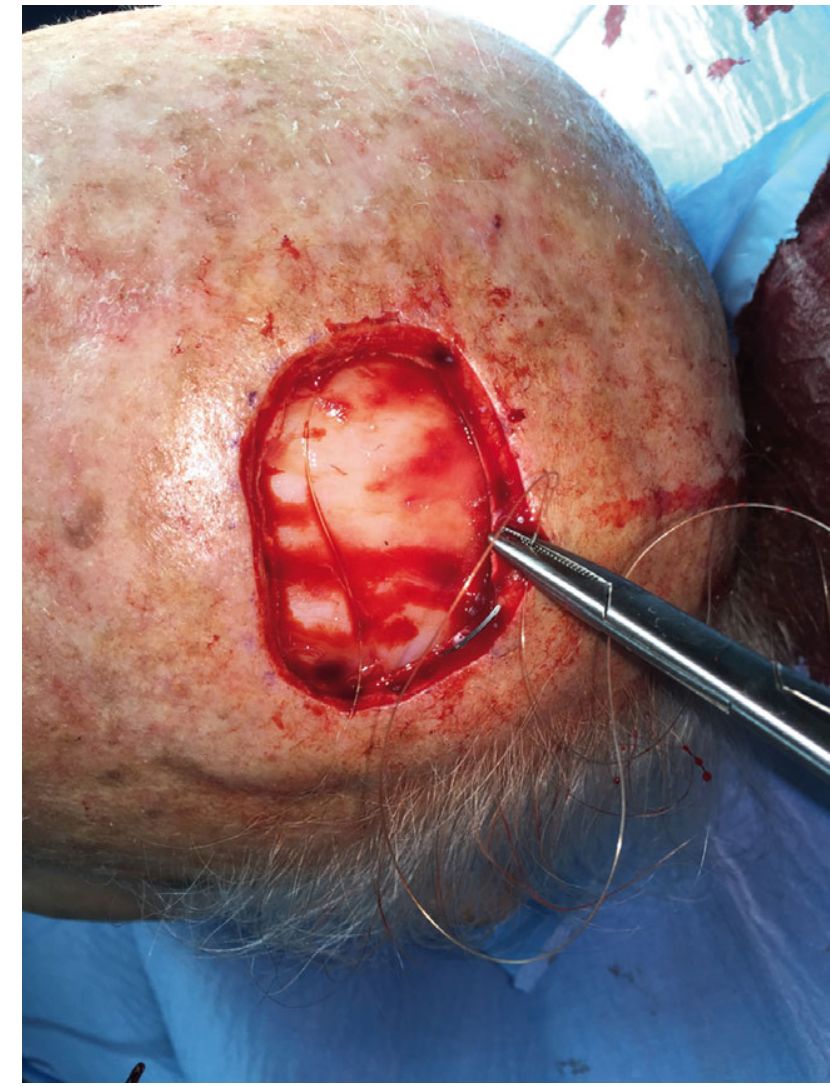

FIGURE 10 Patient 3: Purse string suture technique

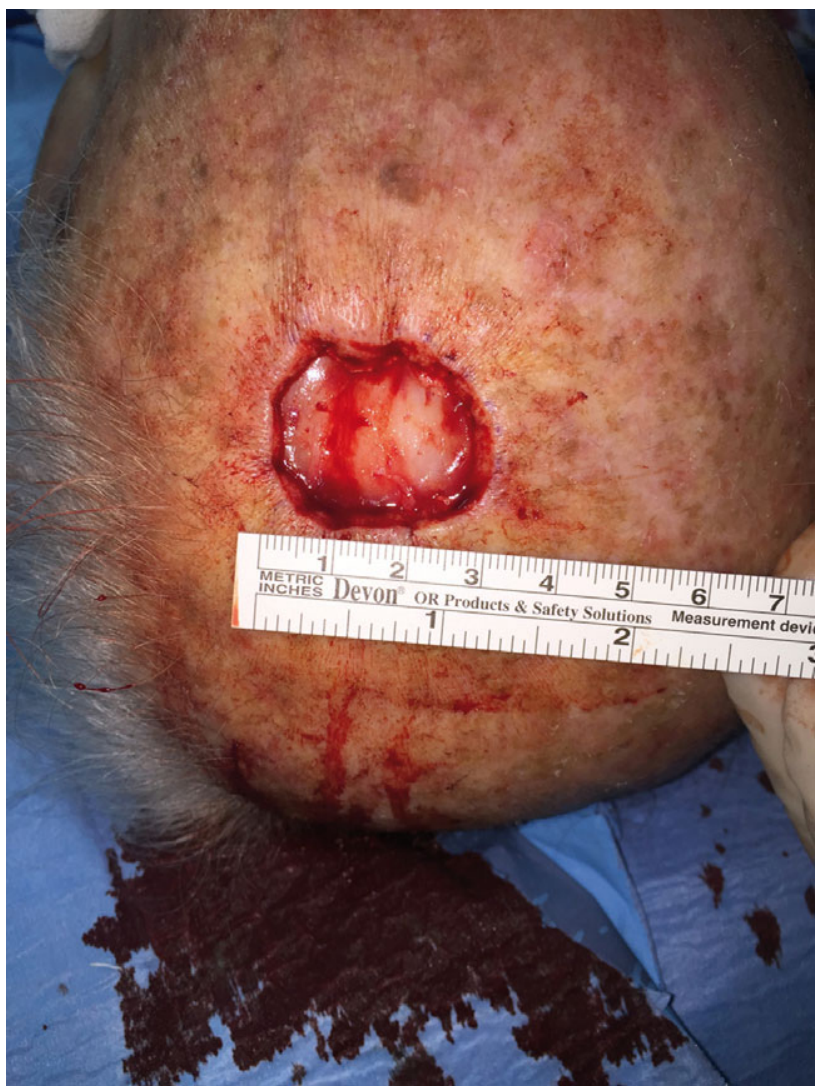

FIGURE 11 Patient 3: The larger diameter was reduced to $3 \mathrm{~cm}$ 


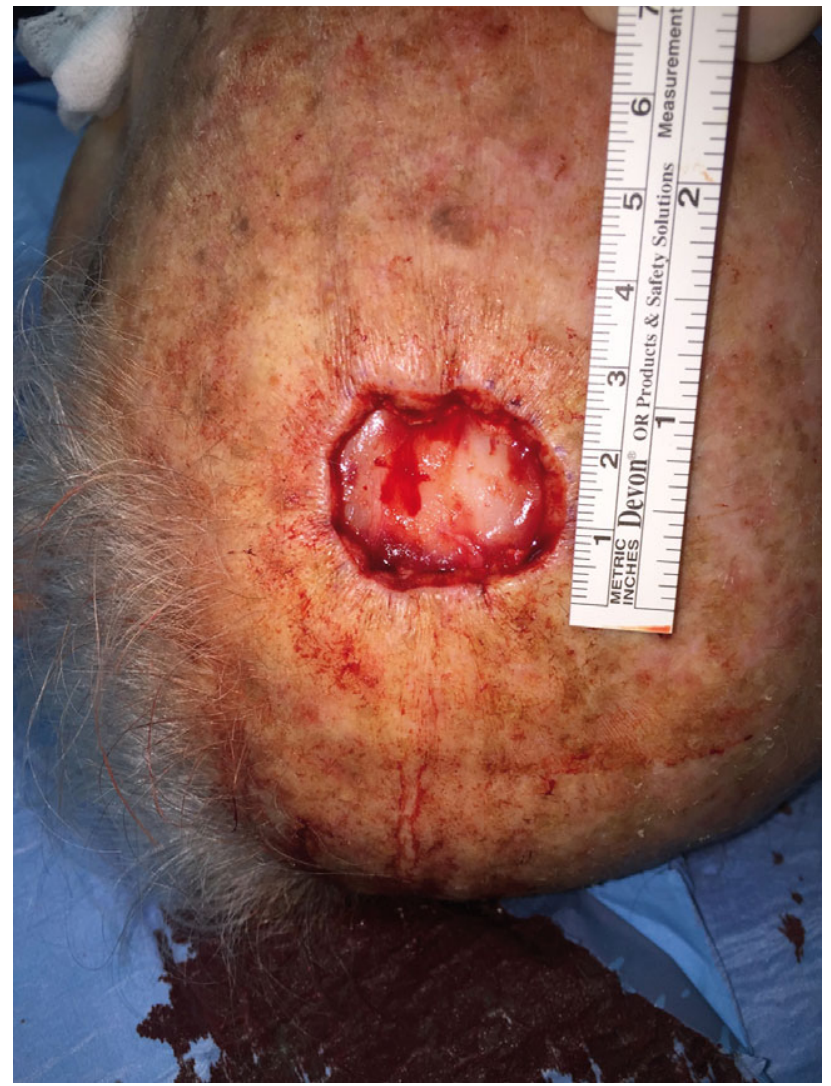

FIGURE 12 Patient 3: The smaller diameter was reduced to $2,5 \mathrm{~cm}$

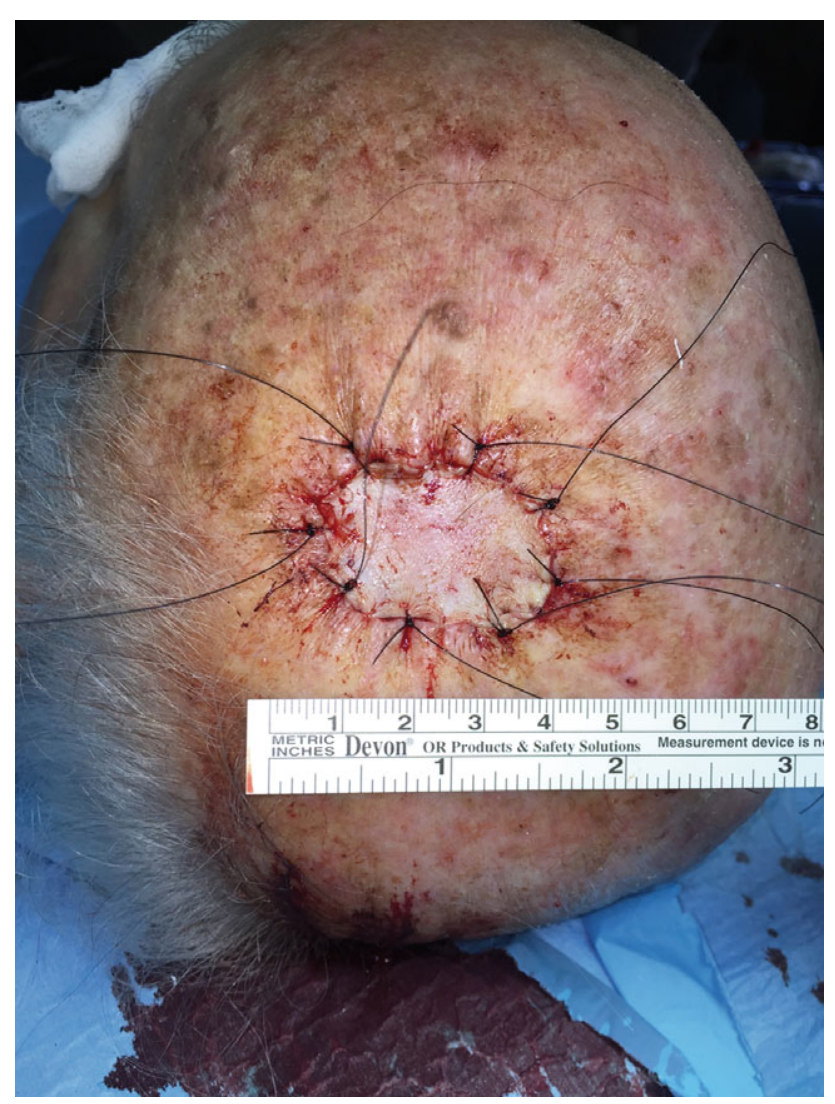

FIGURE 13 Patient 3: The resulting skin defect was closed using a fullthickness skin graft
TABLE 1 Histological results

\begin{tabular}{lc} 
Melanoma & $3(6 \%)$ \\
Squamous cell carcinoma & $6(12 \%)$ \\
Basal cell carcinomas & $36(78 \%)$ \\
Keratoacanthoma & $2(4 \%)$ \\
\hline
\end{tabular}

a fairly constant proportion. The mode was $35 \mathrm{~cm}^{2}$ (8 cases) and the median $34 \mathrm{~cm}^{2}$ (Table 2).

In the early postoperative period, the suture was surrounded by a large number of concentric redundant skin folds, and there was a considerable distortion of the nearby facial structures. Both improved spontaneously over a period of 3 to 5 weeks and had completely disappeared by the time the suture was removed. The central region, while presenting the typical discoloration of grafts, was small and caused cosmetic damage more minor than expected.

Complications included partial graft loss in 3 of the 47 patients (7\%); however, none of these was so significant that it required reoperation and was healed by secondary intention. Another frequent complication was the superficialisation of the suture in 9 patients (21\%), but having used an absorbable suture, the mare watch and wait strategy was adequate.

\section{4 | DISCUSSION}

The original use of the purse string suture, in the early 1950s, is credited to Dr Cannon who used the technique "after excision of a malar sebaceous cyst." Subsequently, closure using the purse string suture was reported to repair surgical defects involving the umbilicus, ${ }^{8}$ urethra, ${ }^{9}$ and breast. $^{10-12}$ The "purse string" closure as the primary method of repair of a cutaneous surgical defect was first introduced by Greenbaum and Radonich in $1996 .{ }^{13}$

The use of the purse string suture is very valuable in lesions of the face and neck. At this level, in aged patients, the skin is loose, and a certain tension may be applied. The primary wound must be circular or oval to allow perfect retraction; it can either be placed horizontally in the dermis (intradermal or subcuticular purse string suture $)^{14-17}$ or be passed through the epidermis and dermis with each stitch (cuticular purse string suture). ${ }^{18}$ Skin from the entire periphery of the defect is uniformly advanced according to the amount of tension placed on the purse string suture; hence, there is not only a maximum advancement of the wound edge but also no distortion of the adjacent structures. ${ }^{14-17}$

It is not necessary to undermine the wound edges when the postoperative surgical defect is partially closed using a cuticular purse string suture. ${ }^{13}$ Advantages of not undermining the surgical wound border when an intradermal pursestring suture is used include allowing the edges to maintain maximum vascularity and permitting the final scar to mature along the natural lines of relaxed skin tension. ${ }^{4,11,13}$ 
TABLE 2 Defect area after excision, after purse string suture (PSS), and gain of area

\begin{tabular}{|c|c|c|c|c|}
\hline Patient & $\begin{array}{l}\text { Defect area } \\
\text { after excision }\end{array}$ & $\begin{array}{l}\text { Defect area } \\
\text { after PSS }\end{array}$ & $\begin{array}{l}\text { Gain of area } \\
\text { to graft }\end{array}$ & $\begin{array}{l}\text { Percentage } \\
\text { gain of } \\
\text { area }(\%)\end{array}$ \\
\hline 1 & 28.6 & 20.1 & 8.5 & 30 \\
\hline 2 & 45.2 & 30.8 & 14.4 & 32 \\
\hline 3 & 20.1 & 15 & 5.1 & 26 \\
\hline 4 & 2 & 1.2 & 0.8 & 40 \\
\hline 5 & 15.4 & 10.2 & 5.2 & 35 \\
\hline 6 & 15.3 & 11.8 & 3.5 & 23 \\
\hline 7 & 11.3 & 8.2 & 3.1 & 28 \\
\hline 8 & 3.85 & 2.2 & 1.65 & 43 \\
\hline 9 & 11.3 & 7.5 & 3.8 & 35 \\
\hline 10 & 25.4 & 17 & 8.4 & 33 \\
\hline 11 & 12.1 & 8 & 4.1 & 34 \\
\hline 12 & 10.4 & 8 & 2.4 & 24 \\
\hline 13 & 4 & 2.6 & 1.4 & 35 \\
\hline 14 & 4.9 & 3 & 1.9 & 38 \\
\hline 15 & 9.4 & 7.4 & 2 & 21 \\
\hline 16 & 5.1 & 3.8 & 1.3 & 26 \\
\hline 17 & 41.5 & 28.2 & 13.3 & 32 \\
\hline 18 & 15.0 & 10 & 5 & 33 \\
\hline 19 & 15.3 & 11.2 & 4.1 & 27 \\
\hline 20 & 41.5 & 30 & 11.5 & 28 \\
\hline 21 & 19.8 & 11.9 & 7.9 & 40 \\
\hline 22 & 4.4 & 3.1 & 1.3 & 29 \\
\hline 23 & 22.6 & 15.2 & 7.4 & 32 \\
\hline 24 & 7.8 & 5 & 2.8 & 36 \\
\hline 25 & 25.4 & 17.8 & 6.6 & 26 \\
\hline 26 & 61.5 & 40 & 21.5 & 35 \\
\hline 27 & 9.8 & 6 & 3.8 & 39 \\
\hline 28 & 15.4 & 9.9 & 5.5 & 36 \\
\hline 29 & 56.5 & 38.3 & 18.2 & 33 \\
\hline 30 & 45.2 & 29.2 & 16 & 35 \\
\hline 31 & 49 & 29 & 20 & 41 \\
\hline 32 & 20.1 & 13.2 & 6.9 & 35 \\
\hline 33 & 21 & 13.7 & 7.3 & 35 \\
\hline 34 & 31.4 & 20.2 & 11.2 & 37 \\
\hline 35 & 34.5 & 22.1 & 12.4 & 36 \\
\hline 36 & 7.5 & 4.9 & 2.6 & 34 \\
\hline 37 & 7.8 & 5 & 2.8 & 36 \\
\hline 38 & 13.2 & 10.1 & 3.1 & 23 \\
\hline 39 & 15.4 & 11.1 & 4.3 & 29 \\
\hline 40 & 17.6 & 12.5 & 5.1 & 30 \\
\hline 41 & 15.4 & 10.8 & 4.6 & 31 \\
\hline 42 & 38 & 25.4 & 12.6 & 33 \\
\hline 43 & 11.3 & 8 & 3.3 & 30 \\
\hline 44 & 25.4 & 16 & 9.4 & 38 \\
\hline 45 & 17.6 & 11.9 & 5.7 & 34 \\
\hline 46 & 21 & 13 & 8 & 38 \\
\hline 47 & 22.6 & 14.8 & 7.8 & 35 \\
\hline Mean area & 21 & 13.9 & 7 & 33 \\
\hline
\end{tabular}

While it is not possible to achieve complete closure of the wound through only the purse string suture technique, a skin graft can be placed in the uncovered area, and it would be smaller than the expected one. In this way, a decreased donor site area and an increased number of full-thickness skin grafts are possible.

Furthermore, the placement of a graft may be preferable to the advancement, rotation, or transposition of a flap in certain oncological skin lesions. ${ }^{19}$ A split-thickness skin graft used as temporary coverage allows the observation of a possible tumour recurrence. In fact, it allows the careful observation both of the area of tumour's excision and margins. These 2 areas of observation are of primary importance because the spread of tumours follows a vertical or centrifugal trend. Ten patients underwent surgery after 1 year to improve the aesthetic result. No reduction of skin elasticity of the area previously closed with purse string sutures was noticed.

This approach has many advantages: first, it is simple, quick, and inexpensive, often demonstrating good final results, particularly in areas of lax skin. In addition, according to Patel and Telfer, although the blood vessels at the periphery of the wound are placed under tension by the closure, those at the base of the wound and, more importantly, those where the vertical edge meets the horizontal base are, to a certain extent, relaxed and may bleed postoperatively. ${ }^{20}$

Moreover, another advantage is that, if something goes wrong with the skin graft, it is easier to manage a small area rather than a larger one. Finally, a skin graft on the scalp lead to alopecia, so the smaller the skin graft is, the better the aesthetic result will be.

In conclusion, the proposed technique allows limiting the skin graft donor site area, thus increasing the possibility of full-thickness grafts thanks to an average area reduction of $33 \%$.

It also permits an optimal follow up both on the bed and the margins of excised cancer.

In addition, complications are rare and easily managed. Finally, the technique is easy to perform, and the learning curve for young surgeon is quick.

\section{ACKNOWLEDGEMENT}

The authors declare that they have no conflict of interest.

\section{REFERENCES}

1. Lo Torto F, Losco L, Bernardini N, Greco M, Scuderi G, Ribuffo D. Surgical treatment with locoregional flaps for the eyelid: a review. Biomed Res Int. 2017;2017:6742537.

2. Ciatti S, Greenbaum SS. Modifie purse-string closure for recostruction o moderate/large surgical defects of the face. Dermatol Surg. 1999;25(3): 215-219.

3. Tromovitch TA, Stegman SJ, Glogau RG. Flaps and Grafts in Dermatologic Surgery. St. Louis, MO: Mosby; 1989.

4. Mulliken JB, Rogers GF, Marler JJ. Circular excision of emangioma and purse-string closure:the smallest possible scar. Plast Reconstr Surg. 2002; 109(5):1544-1554. 
5. Cohen PR, Martinelli PT, Schulze KE, Nelson BR. The purse-string suture revisited: a useful technique for the closure of cutaneous surgical wounds. Int Dermatol. 2007;46(4):241-247.

6. Kawika Weisberg N, Greenbaum SS. Revisiting the purse-string closure: some new methods and modifications. Dermatol Surg. 2003;30(9):1275-1277.

7. Hirshowitz B, Lindenbaum E. "Sure-closure" skin stretching system. Plast Reconstr Surg. 1999;103(1):332-333.

8. Marconi F. Reconstruction of the umbilicus: a simple technique. Plast Reconstr Surg. 1995;95:1115-1117.

9. Fatah MF. A method of closing urethral fistulae using a purse-string or interrupted silk sutures. Br J Plast Surg. 1982;35:102-103.

10. Marconi $F$. The dermal pursestring suture: a new technique for a short inframammary scar in reduction mammaplasty and dermal mastopexy. Ann Plast Surg. 1989;22:484-493.

11. Persichetti P, Berloco M, Casadei RM, Marangi GF, Lella FD, Nobili AM. Gynecomastia and the complete circumareolar approach in the surgical management of skin redundancy. Plast Reconstr Surg. 2001;107:948-954.

12. Toth BA, Daane SP. Purse-string mastectomy with immediate prosthetic reconstruction: an improbe skin-sparing technique for small breasts. Plast Reconstr Surg. 2003;111:2333-2337.

13. Greenbaum SS, Radonich MA. The purse-string closure. Dermatol Surg. 1996;22:1054-1056.

14. Siegert R, Weerda H, Hoffmann S, Mohadjer C. Clinical and experimental evaluation of intermittent intraoperative short-term expansion. Plast Reconstr Surg. 1993;92:248-254.
15. Mather MK, Harrington AC, Montemarano A, Farley M. Surgical pearl: purse-string suture in the management of poorly delinated melanomas. J Am Acad Dermatol. 1998;38:99-101.

16. Yuen JC. Versatility of the subcuticular purse-string suture in wound closure. Plast Reconstr Surg. 1996;98:1302-1305.

17. Tremolada C, Blandini D, Beretta M, Mascetti M. The "round block" purse-string suture: a simple method to close skin defects with minimal scarring. Plast Reconstr Surg. 1997;100:126-131.

18. Mulliken JB, Rogers GF, Marler JJ. Circular excision of hemangioma and purse-string closure: the smallest possible scar. Plast Reconstr Surg. 2002; 109:1544-1554.

19. Tarallo M, Cigna E, Frati R, et al. Metatypical basal cell carcinoma: a clinical review. J Exp Clin Cancer Res. 2008;27:65.

20. Patel KK, Telfer MR, Southee R. A "round block" purse-string suture in facial reconstruction after operations for skin cancer surgery. Br J Oral Maxillofac Surg. 2003;41(3):151-156.

How to cite this article: Fioramonti P, Sorvillo V, Maruccia M, et al. New application of purse string suture in skin cancer surgery. Int Wound J. 2018;15: 893-899. https://doi.org/10.1111/iwj.12941 